\title{
Mössbauer spectroscopy with a high velocity resolution applied for the study of meteoritic iron-bearing minerals
}

\author{
M.I. Oshtrakh ${ }^{\mathrm{a}, \mathrm{b}, *}$, V.I. Grokhovsky ${ }^{\mathrm{a}, \mathrm{b}}$, E.V. Petrova ${ }^{\mathrm{a}}$, M.Yu. Larionov ${ }^{\mathrm{a}, \mathrm{b}}$, M.V. Goryunov ${ }^{\mathrm{a}, \mathrm{b}}$, \\ V.A. Semionkin ${ }^{\mathrm{a}, \mathrm{b}}$ \\ a Department of Physical Techniques and Devices for Quality Control, Institute of Physics and Technology, Ural Federal University, Ekaterinburg 620002, Russian Federation \\ ${ }^{\mathrm{b}}$ Department of Experimental Physics, Institute of Physics and Technology, Ural Federal University, Ekaterinburg 620002, Russian Federation
}

\section{A R T I C L E I N F}

\section{Article history:}

Available online 2 October 2012

\section{Keywords:}

Mössbauer spectroscopy with a high

velocity resolution

Iron-bearing phases

Meteorites

\begin{abstract}
A B S T R A C T
Mössbauer spectroscopy with a high velocity resolution was applied for study of iron-bearing minerals in different meteorites. The possibility of technique to reveal small variations in Mössbauer hyperfine parameters of the ${ }^{57} \mathrm{Fe}$ in the non-equivalent M1 and M2 sites in olivines from Farmington L5 and Tsarev L5 ordinary chondrites and from Omolon and Seymchan pallasites was demonstrated. The necessity of accounting for the Fe and Ni occupation probabilities in the local microenvironments for non-equivalent sites M1, M2 and M3 in schreibersite, an iron nickel phosphide from Sikhote-Alin iron meteorite, in the fit of its Mössbauer spectra was shown. Variations in Mössbauer parameters of metal samples from visually different areas at the saw-cut surface of Chinga iron meteorite fragment with unknown origin were observed; these variations may be related to different metal phase composition and local variations of $\mathrm{Ni}$ concentration in the metal phases in these areas.
\end{abstract}

(C) 2012 Elsevier B.V. All rights reserved.

\section{Introduction}

Various meteorites (iron, stony-iron and stone meteorites) contain iron-bearing minerals such as kamacite and taenite ( $\mathrm{Fe}-\mathrm{Ni}$ alloys), olivine ( $\mathrm{Fe}, \mathrm{Mg})_{2} \mathrm{SiO}_{4}$, pyroxene ( $\left.\mathrm{Fe}, \mathrm{Mg}, \mathrm{Ca}\right) \mathrm{SiO}_{3}$, troilite $\mathrm{FeS}$, schreibersite $(\mathrm{Fe}, \mathrm{Ni})_{3} \mathrm{P}$ and so on. These minerals were formed in the unique space conditions which cannot be reproduced in terrestrial conditions. Therefore, these minerals are interesting for understanding their physical features. Mössbauer spectroscopy is a useful tool for analysis of the iron-bearing phases and used for a long time in these investigations (see, for instance, [1-3]). However conventional Mössbauer spectrometers allow researchers to register spectra in 512 or 256 channels mainly (with a low velocity resolution). In this case it is not possible to reach very good fit of complicated Mössbauer spectra while the instrumental (systematic) error of the velocity scale is too large to distinguish small variations in hyperfine parameters. Further development of Mössbauer spectrometers to increase velocity resolution up to 4096 channels (a high velocity resolution) in the spectrum leads to decrease in the instrumental (systematic) error on the velocity scale and better fit of complicated Mössbauer spectra due to increase in the number of spectral points (see technical advances in [4-6]). Study of meteor-

\footnotetext{
* Corresponding author at: Department of Physical Techniques and Devices for Quality Control, Institute of Physics and Technology, Ural Federal University, Ekaterinburg 620002, Russian Federation.
}

E-mail address: oshtrakh@mail.utnet.ru (M.I. Oshtrakh). ites and its iron-bearing phases using Mössbauer spectroscopy with a high velocity resolution demonstrated new possibilities in revealing data which could not be obtained from Mössbauer spectra measured with a low velocity resolution [7-20]. Therefore, in this work we consider further results of the study of some ironbearing minerals from some meteorites obtained using Mössbauer spectroscopy with a high velocity resolution.

\section{Materials and methods}

Fragments of Tsarev L5 and Farmington L5 equilibrated ordinary chondrites were used for preparation of powdered samples of the bulk meteorites. Olivine samples were mechanically extracted from fragments of Omolon and Seymchan the main-group pallasites and powdered with removing of magnetic fraction remains using magnet. A sample of schreibersite was mechanically extracted from the bulk fragment of Sikhote-Alin (IIAB) iron meteorite with further $\mathrm{HCl}$ treatment to remove residual kamacite $\alpha-\mathrm{Fe}(\mathrm{Ni}, \mathrm{Co})$. Four metal samples from visually different areas of saw-cut surface of the fragment of Chinga iron meteorite marked $1,2,3$ and 5 were prepared in the form of powder in the same conditions. Powder samples for Mössbauer measurements were glued on aluminum foil free from iron with diameter of $2 \mathrm{~cm}$. The thickness of all samples was within the limit of thin absorber.

All samples were characterized by X-ray diffraction using XRD7000 powder diffractometer (Shimadzu) operated at $40 \mathrm{kV}$ and $30 \mathrm{~mA}$ with Ni-filtered $\mathrm{Cu} \mathrm{K} \alpha$ radiation, STADI-P diffractometer 

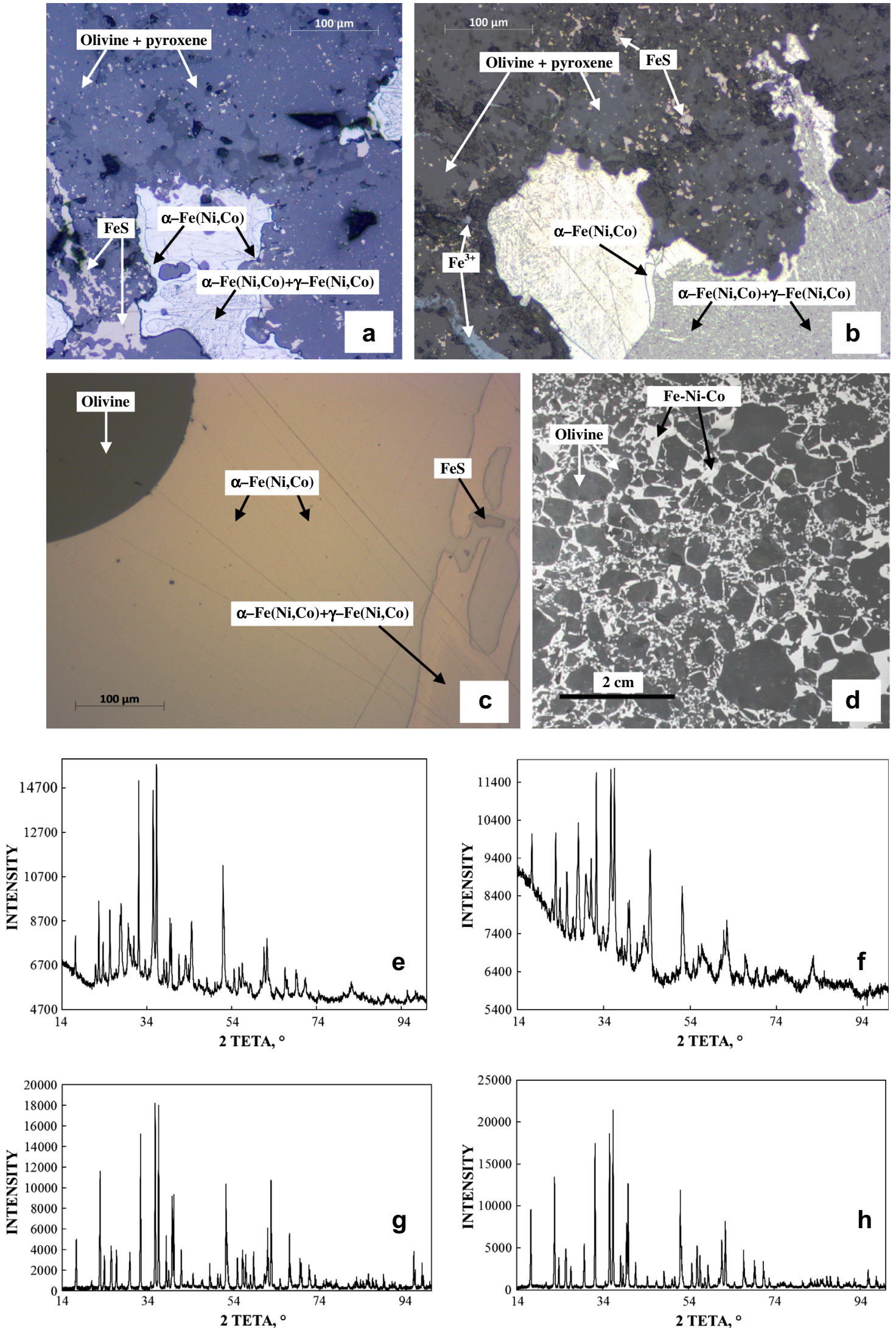

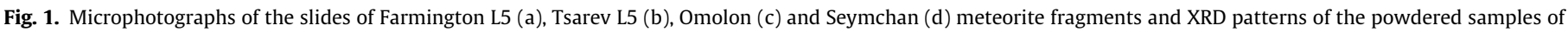
Farmington L5 (e), Tsarev L5 (f), Omolon (g) and Seymchan (h) meteorite fragments.

with $\mathrm{Cu} \mathrm{K} \alpha_{1}$ radiation and X'Pert PRO MRD diffractometer with $\mathrm{Cu}$ $\mathrm{K} \alpha$ radiation for the phase control. Ordinary chondrites and palla- sites were analyzed by metallography. Scanning electron microscopy (SEM) with energy dispersion spectroscopy (EDS) were used 
for schreibersite and Chinga metal characterization using Philips 30XL with EDS and $\Sigma$ IGMA VP (Carl Zeiss) with EDS microscopes.

Mössbauer spectra were measured using an automated precision Mössbauer spectrometric system built on the base of the SM2201 spectrometer with a saw-tooth shape velocity reference signal formed using 4096 bits. Details and characteristics of this spectrometer and the system were given in [4-6]. The Mössbauer spectra were measured in transmission geometry with moving absorber in the cryostat at 295 and $90 \mathrm{~K}$ and recorded in 4096 channels. The $1.8 \times 10^{9} \mathrm{~Bq}^{57} \mathrm{Co}$ in rhodium matrix (Ritverc GmbH, St. Petersburg) was used at room temperature. Spectra of olivines from pallasites were measured in velocity range of about $\pm 4 \mathrm{~mm} / \mathrm{s}$ with statistical count rate ranged from $\sim 1.9 \times 10^{5}$ to $\sim 2.4 \times 10^{5}$ counts per channel and the signal-to-noise ratio varied from 63 to 74 in the spectra presented in 4096 channels. Mössbauer spectra of ordinary chondrites and schreibersite were measured in a larger velocity range (from \pm 8 to $\pm 10 \mathrm{~mm} / \mathrm{s}$ ). For their analysis, these spectra were converted into 2048 channels by a consequent summation of two neighboring channels. Statistical count rate in the spectra presented in 2048 channels ranged from $\sim 8.1 \times 10^{5}$ to $\sim 4.2 \times 10^{6}$ counts per channel and the signal-to-noise ratio varied from 117 to 220 for ordinary chondrites as well as $\sim 5.3 \times 10^{5}$ and $\sim 2.7 \times 10^{6}$ counts per channel with the signal-to-noise ratio of 26 and 40 for schreibersite at 90 and $295 \mathrm{~K}$, respectively. Mössbauer spectra of Chinga metal samples were measured in a large velocity range of $\pm 8 \mathrm{~mm} / \mathrm{s}$ at room temperature and remained in 4096 channels with statistical count rate ranged from $\sim 1.6 \times 10^{6}$ to $\sim 1.8 \times 10^{6}$ counts per channel and the signal-to-noise ratio varied from 72 to 96 . The spectra were computer fitted with the least squares procedure using UNIVEM-MS program with a Lorentzian line shape. The spectral parameters such as: isomer shift, $\delta$, quadrupole splitting (quadrupole shift for magnetically split spectra), $\Delta E_{\mathrm{Q}}$, magnetic hyperfine field, $H_{\mathrm{eff}}$, line width, $\Gamma$, relative subspectrum area, $S$, and statistical quality of the fit, $\chi^{2}$, were determined. An instrumental (systematic) error for each spectrum point was \pm 0.5 channel (the velocity scale), the instrumental (systematic) error for the hyperfine parameters was \pm 1 channel. The error for $\mathrm{S}$ did not exceed $10 \%$. If an error calculated with the fitting procedure (fitting error) for these parameters exceeded the instrumental (systematic) error, we used the larger error instead. Criteria of the best fits were differential spectrum, $\chi^{2}$ and physical meaning of parameters. Values of $\delta$ are given relative to $\alpha$-Fe at $295 \mathrm{~K}$.
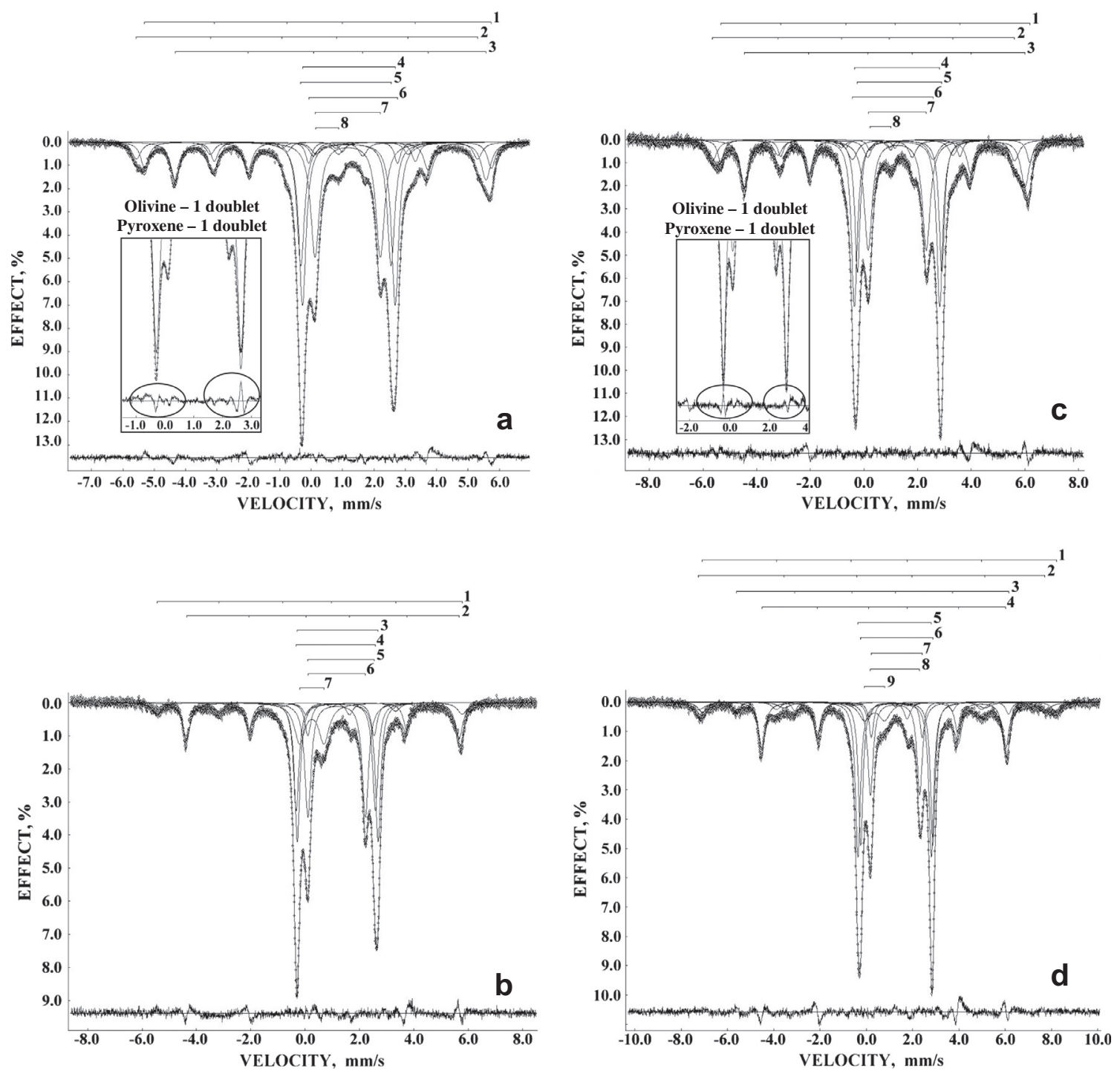

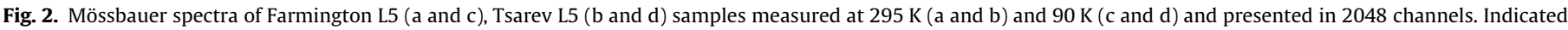
components are the results of the best fits. Differential spectra are shown below. 


\section{Results and discussion}

3.1. Olivines from Omolon and Seymchan pallasites and Farmington L5 and Tsarev L5 ordinary chondrites

The microphotographs of the slides of ordinary chondrites (Farmington L5 and Tsarev L5) and pallasites (Omolon and Seymchan) are shown in Fig. 1a-d. It is clearly seen in these microphotographs that Farmington L5 consists of metal phase formed by kamacite $\alpha$-Fe( $\mathrm{Ni}, \mathrm{Co})$ and plessite structure $\alpha-\mathrm{Fe}(\mathrm{Ni}, \mathrm{Co})+\gamma-\mathrm{Fe}(\mathrm{Ni}$, $\mathrm{Co})$, silicate phase contained olivine $(\mathrm{Fe}, \mathrm{Mg})_{2} \mathrm{SiO}_{4}$ and pyroxene $(\mathrm{Fe}, \mathrm{Mg}, \mathrm{Ca}) \mathrm{SiO}_{3}$, and troilite $\mathrm{FeS}$ while Tsarev L5 contains also a large amount of $\mathrm{Fe}^{3+}$ compound in addition to mentioned phases. The Omolon and Seymchan pallasites consist of metal and olivine grains, however, the grain size in Seymchan was significantly larger. It should be noted that both silicate phases contain two crystallographically non-equivalent six-fold octahedral sites for $\mathrm{Fe}^{2+}$ and $\mathrm{Mg}^{2+}$ denoted as M1 and M2. These sites in olivine and pyroxene are occupied by $\mathrm{Fe}^{2+}$ and $\mathrm{Mg}^{2+}$ ions in different ways (see [13]). The XRD patterns of Farmington L5, Tsarev L5 and olivines extracted from Omolon and Seymchan are shown in Fig. 1e-h. Their Rietveld analysis showed that ordinary chondrites have the same phase composition with olivine, pyroxene, troilite and metal phase, however, olivine content in Farmington L5 was found larger than in Tsarev L5. It was not possible to distinguish peaks related to $\mathrm{Fe}^{3+}$ compound in the XRD pattern for Tsarev L5 probably due to their coincidence with other more intensive peaks. The olivine sample extracted from Omolon contains a mixture of three phases: the main phase of about $94 \mathrm{wt} . \%$ of $(\mathrm{Fe}, \mathrm{Mg})_{2} \mathrm{SiO}_{4}$ with orthorhombic crystal lattice parameters: $a=10.2337(7) \AA, b=5.9969(5) \AA$, $c=4.7641$ (3), about 2 wt.\% of $\mathrm{FeS}$ and about 4 wt.\% of $\mathrm{SiO}_{2}$. The olivine sample extracted from Seymchan contains two phases: the main phase of about $97 \mathrm{wt} . \%$ of $(\mathrm{Fe}, \mathrm{Mg})_{2} \mathrm{SiO}_{4}$ with orthorhombic crystal lattice parameters: $a=10.2267(7) \AA$, $b=5.9939(4) \AA$, $c=4.7623(3) \AA$ and about 3 wt.\% of $\mathrm{SiO}_{2}$. It is interesting that crystal lattice parameters $a, b$ and $c$ appeared to be different for olivines extracted from Omolon and Seymchan.

Mössbauer spectra of Farmington L5 and Tsarev L5 measured at 295 and $90 \mathrm{~K}$ are shown in Fig. 2. These spectra consisted of several magnetic sextets and quadrupole doublets correspondent to the main iron-bearing phases in ordinary chondrites. Mössbauer spectra of Farmington L5 and Tsarev L5 were fitted using one sextet for troilite component, one or two sextets to fit metal phase, two pairs of quadrupole doublets for both olivine and pyroxene components related to the ${ }^{57} \mathrm{Fe}$ in the M1 and M2 sites in silicates, and one quadrupole doublet for ferric component for Farmington L5 spectra measured at 295 and $90 \mathrm{~K}$ and Tsarev L5 spectrum at $295 \mathrm{~K}$ and one quadrupole doublet and two magnetic sextets for Tsarev L5 spectrum at $90 \mathrm{~K}$. The necessity of two pairs of quadrupole doublets for olivine and pyroxene components was confirmed by decrease in $\chi^{2}$ values and improving of differential spectra in comparison with the fit using one quadrupole doublet for each olivine and pyroxene component. For instance, in the case of the fit of the Farmington L5 spectrum using one doublet for both
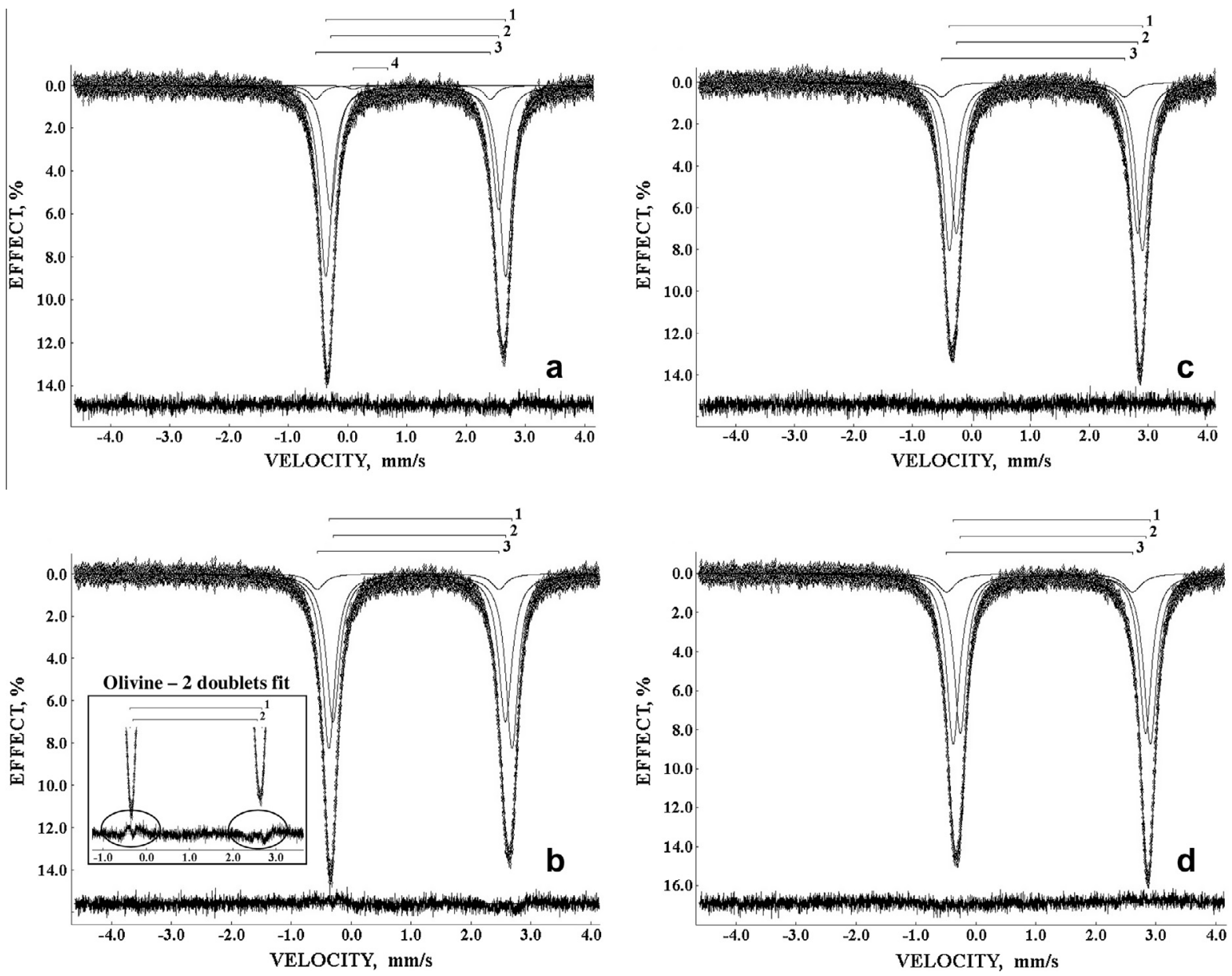

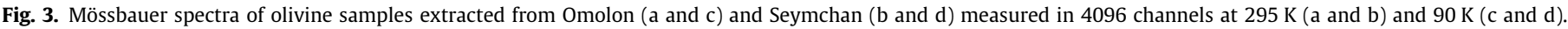
Indicated components are the results of the best fits. Differential spectra are shown below. 

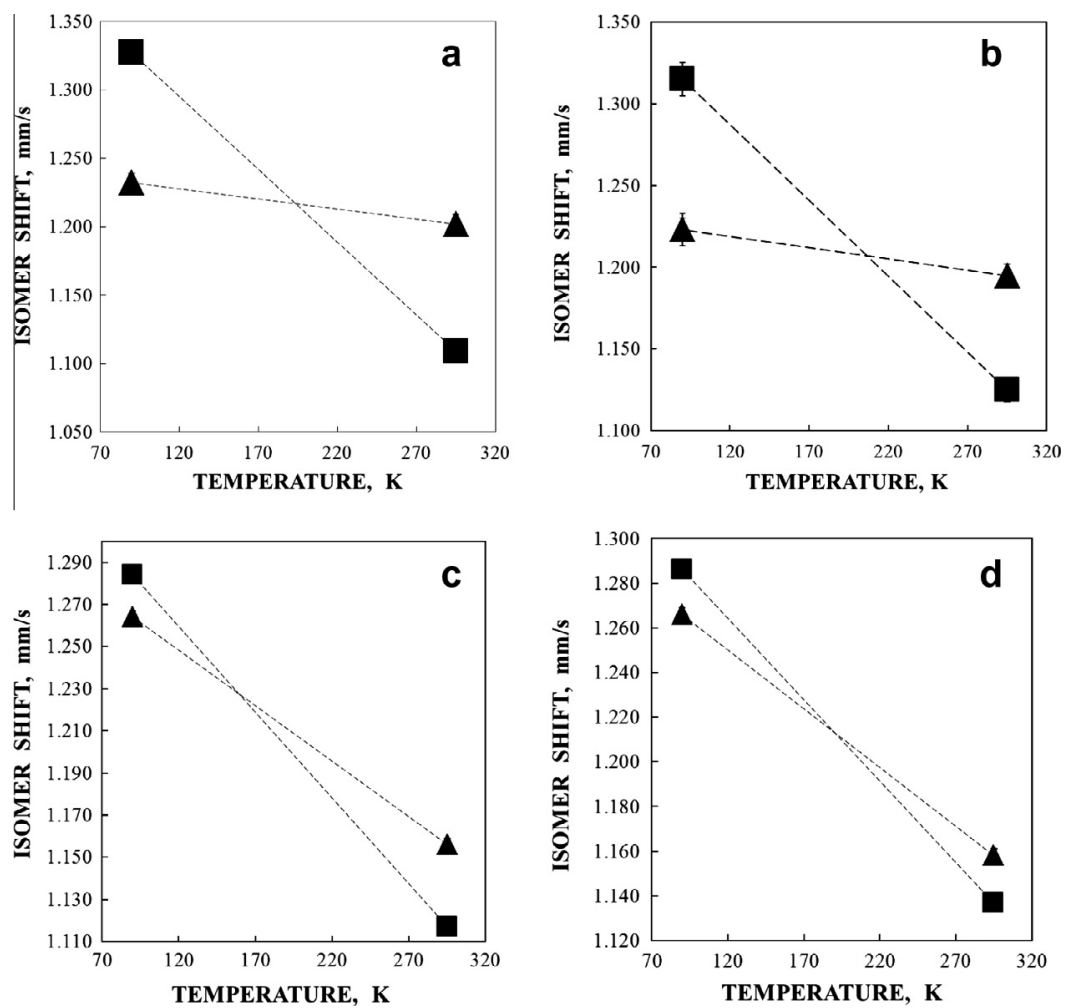

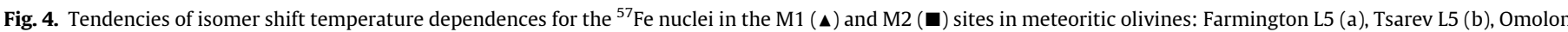
(c) and Seymchan (d).
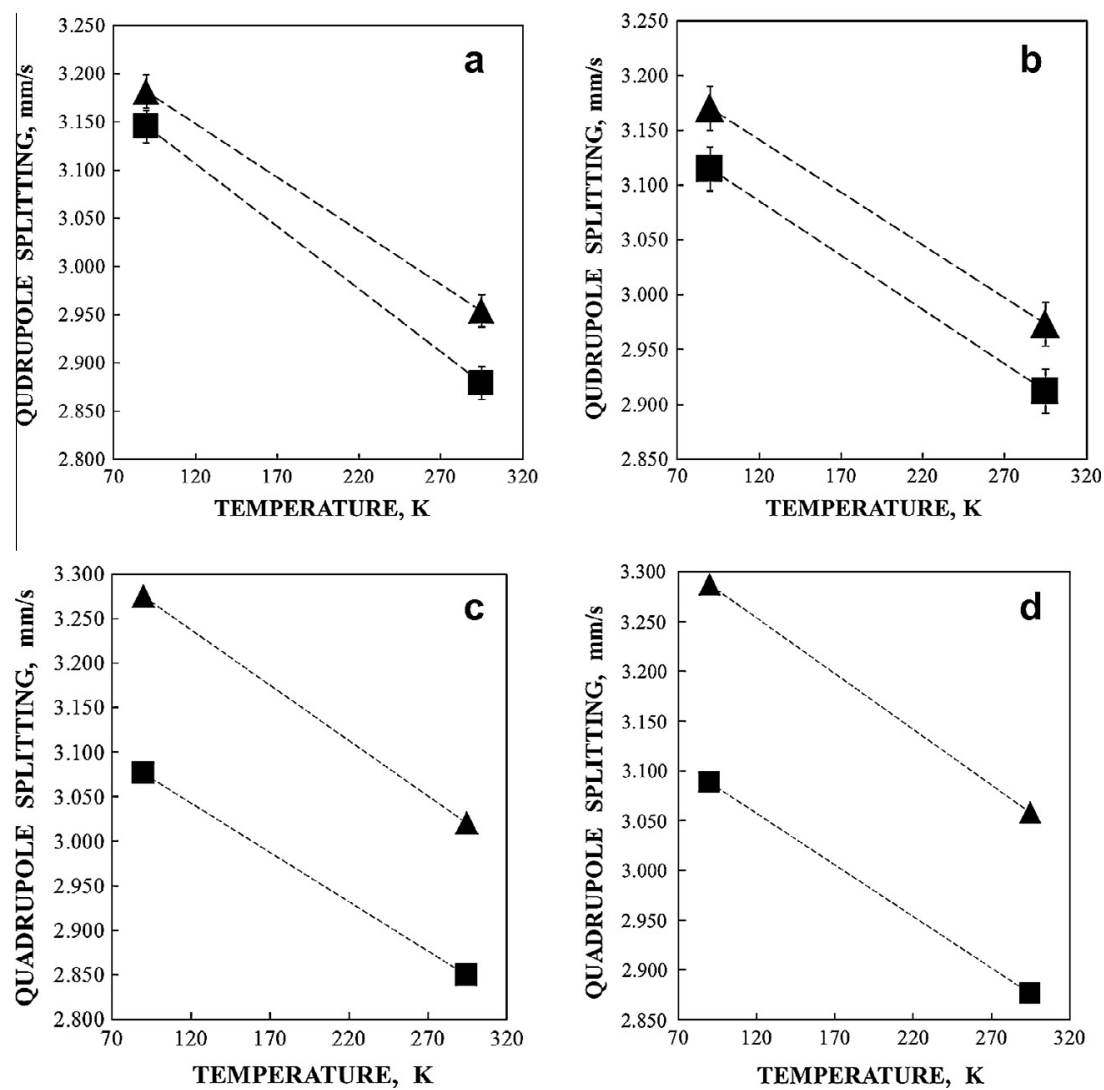

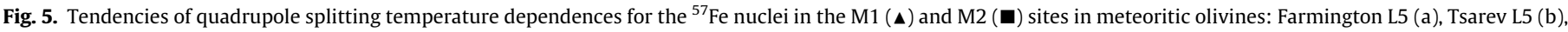
Omolon (c) and Seymchan (d). 

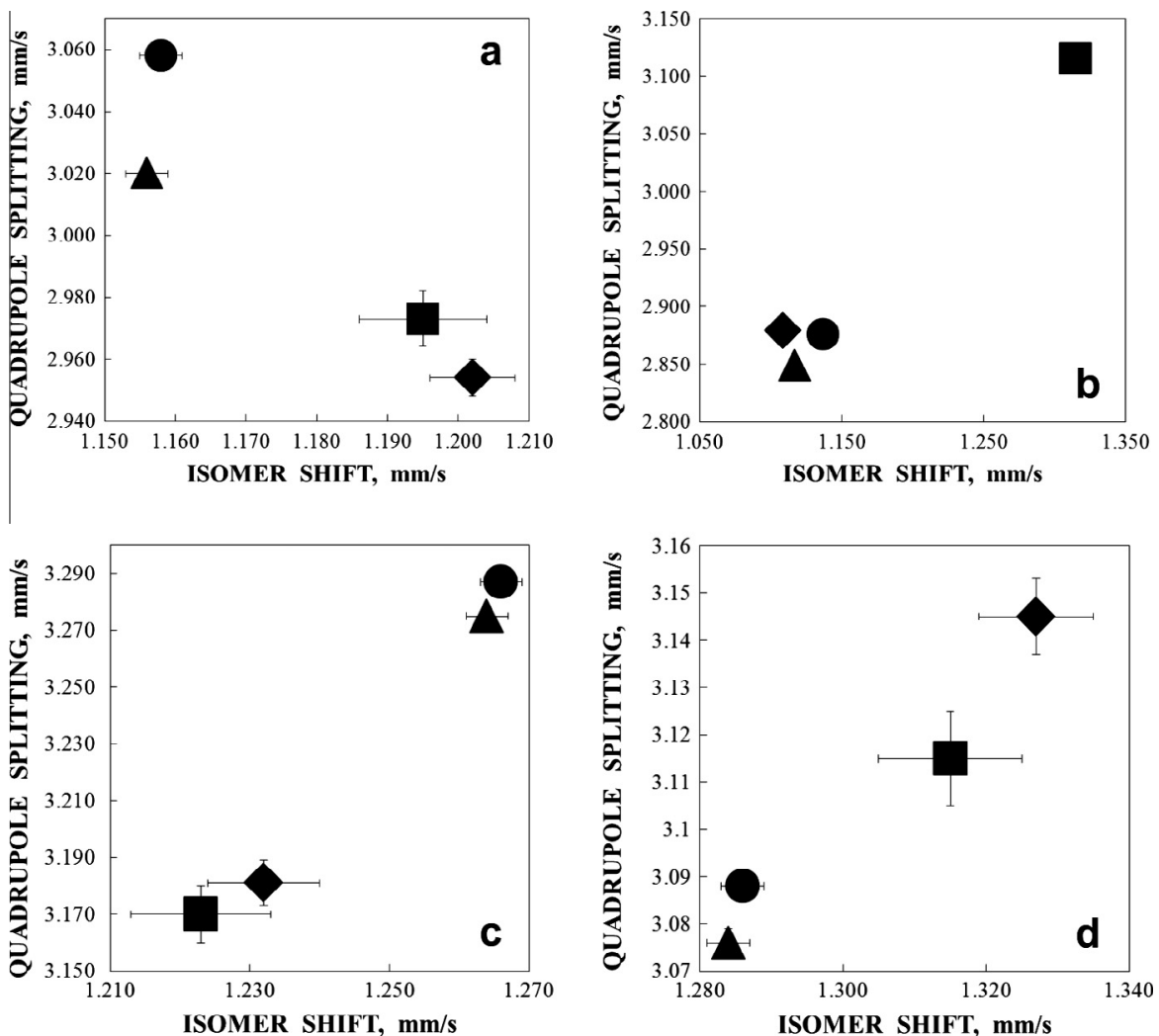

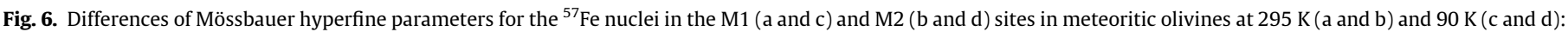

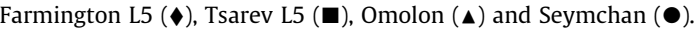
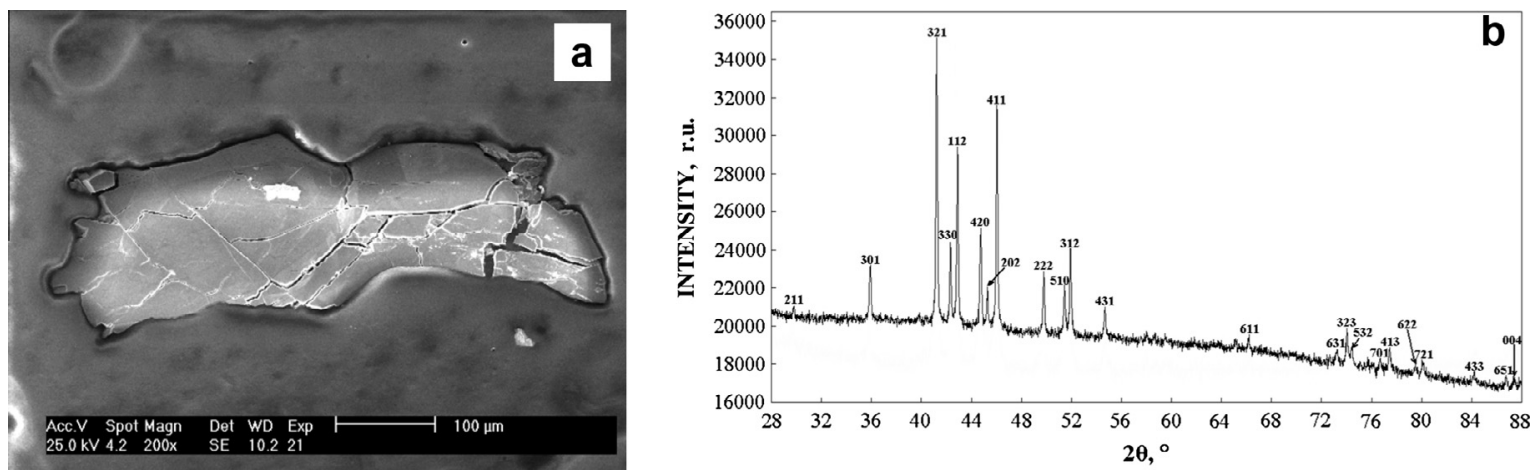

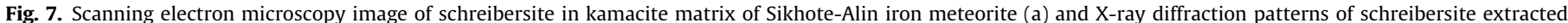
from Sikhote-Alin meteorite (b).

olivine and pyroxene the value of $\chi^{2}$ was 7.16 while in the case of the best fit $\chi^{2}$ was 3.51, a significant improving of differential spectra is clearly seen in Fig. 2a and b as well. As for olivine subspectra, the quadrupole doublet with larger $S$ was assigned to the ${ }^{57} \mathrm{Fe}$ in the M1 sites while that with smaller $S$ was assigned to the ${ }^{57} \mathrm{Fe}$ in the M2 sites due to well-known fact of slightly larger $\mathrm{Fe}^{2+}$ occupancy in the M1 sites of olivine [13].

Mössbauer spectra of olivines extracted from Omolon and Seymchan meteorites measured at 295 and $90 \mathrm{~K}$ are shown in Fig. 3. Mössbauer spectra were fitted with several numbers of quadrupole doublets. The best fit of the room temperature spectrum of olivine from Omolon demonstrated the presence of 4 components related to three ferrous (1-3) and one ferric (4) compounds. We suppose that the minor ferric compound $(S=1 \%)$ represents residual oxidized metal particles remained in olivine after magnetic separation. The values of $\chi^{2}$ for this spectrum different fits were 1.541 ( 1 doublet fit, deviation of $\chi^{2}$ was $24.5 \sigma$ ), 1.078 ( 2 doublets fit, deviation of $\chi^{2}$ was $3.5 \sigma$ ), 1.067 ( 3 doublets fit, deviation of $\chi^{2}$ was $3.0 \sigma$ ), and 0.975 ( 4 doublets fit, deviation of $\chi^{2}$ was $1.1 \sigma$ ). The differential spectra in these fits clear indicated the necessity of 4 quadrupole doublets for the best fit. In contrast, the Mössbauer spectrum of olivine from Omolon measured at $90 \mathrm{~K}$ was better fitted using 3 components only which were related to three ferrous compounds (1-3). It is possible that the minor ferric paramagnetic component after cooling down to $90 \mathrm{~K}$ transferred to magnetically split component with intensities of internal sextet lines within the spectral noise (the relative area of this six-line component should be about the same as paramagnetic doublet at $295 \mathrm{~K}$, i.e. $\sim 1 \%$ ) that is why we did not found this component in the spectrum measured in a small velocity range. It should be 

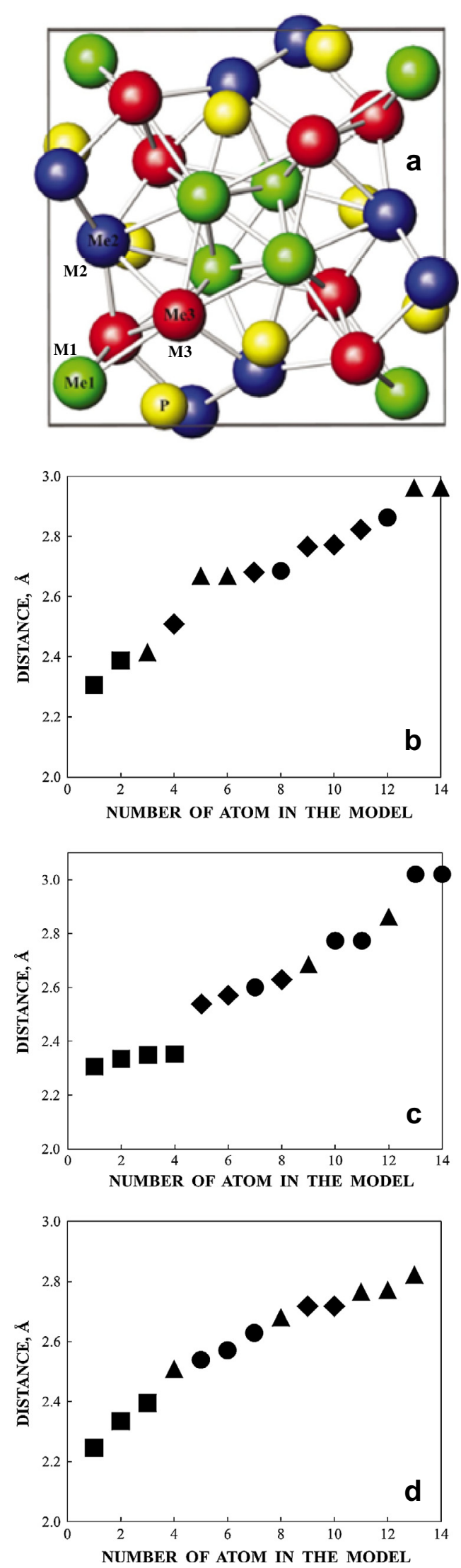

Fig. 8. Structural model of the unit cell in schreibersite from Sikhote-Alin iron meteorite (a) and local microenvironment of the M1 (b), M2 (c) and M3 (d) sites: - P atom, $\mathbf{\Delta}-$ M1 site (Fe atom), $\bullet-$ M2 site (Fe or Ni atoms), - M3 site (Fe or Ni atoms). noted that the third additional minor component related to the unknown high spin ferrous compound was obtained from the fit of these spectra at both temperatures. The necessity of this minor component marked $X$ was confirmed by comparison of the $\chi^{2}$ values and differential spectra. For instance, a comparison of two fits of the room temperature Mössbauer spectrum of olivine extracted from Seymchan using two and three quadrupole doublets showed that the $\chi^{2}$ values were 1.208 (deviation of $\chi^{2}$ was $9.5 \sigma$ ) and 1.106 (deviation of $\chi^{2}$ was $4.8 \sigma$ ), respectively, and differential spectrum became more linear for the three doublets fit (Fig. 3b). The components of Mössbauer spectra of olivine extracted from pallasites were related to the ${ }^{57} \mathrm{Fe}$ in the M1 and M2 sites in the same way like the spectral components of olivine in ordinary chondrites. It should be noted that the minor ferrous component 3 (about 5-7\%) was related to the distorted M1 sites (and denoted as M1a sites) on the basis of evaluation of the temperature of cation equilibrium distribution (see [17]).

The tendencies of temperature dependences of $\delta$ and $\Delta E_{\mathrm{Q}}$ for olivines in ordinary chondrites and extracted from pallasites are shown in Figs. 4 and 5. The tendencies of $\delta$ temperature dependences for the ${ }^{57} \mathrm{Fe}$ in $\mathrm{M} 1$ and $\mathrm{M} 2$ sites of olivines demonstrated crossing in the range of about $150-230 \mathrm{~K}$. It is well known that temperature dependence of $\delta$ is related to the second order Doppler shift. Therefore, this result indicates that the Debye temperature for the ${ }^{57} \mathrm{Fe}$ in different sites is different, i.e. the dynamic characteristics of the ${ }^{57} \mathrm{Fe}$ nuclei in the M1 and M2 sites are different. The values of $\Delta E_{\mathrm{Q}}$ for the ${ }^{57} \mathrm{Fe}$ in the both M1 and M2 sites in the studied olivines characterize the high spin ferrous iron. Therefore, an increase of the electric field gradient with temperature decrease may be related to the presence of the low-lying electron terms which produce the electric field gradient with opposite sign than the ground one. It was interesting that the difference between $\Delta E_{\mathrm{Q}}$ values for the ${ }^{57} \mathrm{Fe}$ in the M1 and M2 sites of olivines in Farmington L5 and Tsarev L5 chondrites was significantly less than that for the ${ }^{57} \mathrm{Fe}$ in the M1 and M2 sites of olivines extracted from Omolon and Seymchan pallasites. This finding indicates that $\mathrm{Fe}^{2+}$ microenvironment for the M1 and M2 sites of olivines in ordinary chondrites has less difference than that of olivines extracted from pallasites. Moreover, it was possible to distinguish different olivines in the plots of Mössbauer hyperfine parameters for the ${ }^{57} \mathrm{Fe}$ in the M1 and M2 sites of olivines in bulk Farmington L5 and Tsarev L5 and extracted from Omolon and Seymchan pallasites (Fig. 6). This result indicates that the local environment in the M1 and M2 sites vary in olivines with different origin and correlates with XRD results for olivines from pallasites.

\subsection{Schreibersite from Sikhote-Alin iron meteorite}

SEM image of schreibersite macroinclusion in kamacite matrix of Sikhote-Alin iron meteorite is shown in Fig. 7a. EDS showed that the average $\mathrm{Fe}$ and $\mathrm{Ni}$ concentration ratio in schreibersite was of 64\%:36\%. XRD patterns of schreibersite extracted from Sikhote-Alin meteorite are shown in Fig. 7b. These data showed that schreibersite has tetragonal space group 14 with the unit cell parameters $a=9.049(8) \AA$ and $c=4.461(8) \AA$ with three crystallographically different sites for metal atoms denoted as M1, M2 and M3 and the unit cell with 8 atoms in each site (see Fig. 8a). Previous study [19] was performed on the basis of the model [21] suggesting the magnetic moment splitting of about $0.1 \mu_{\mathrm{B}}$ for each site in iron phosphide as a reason of two sextets related to the ${ }^{57} \mathrm{Fe}$ in each M1, M2 and M3 site. Therefore, Mössbauer spectra of schreibersite presented in 1024 channels were fitted using six magnetic sextets each pair of which was related to the ${ }^{57} \mathrm{Fe}$ in the M1, M2 and M3 sites. However, in contrast to iron phosphide the sample of iron 

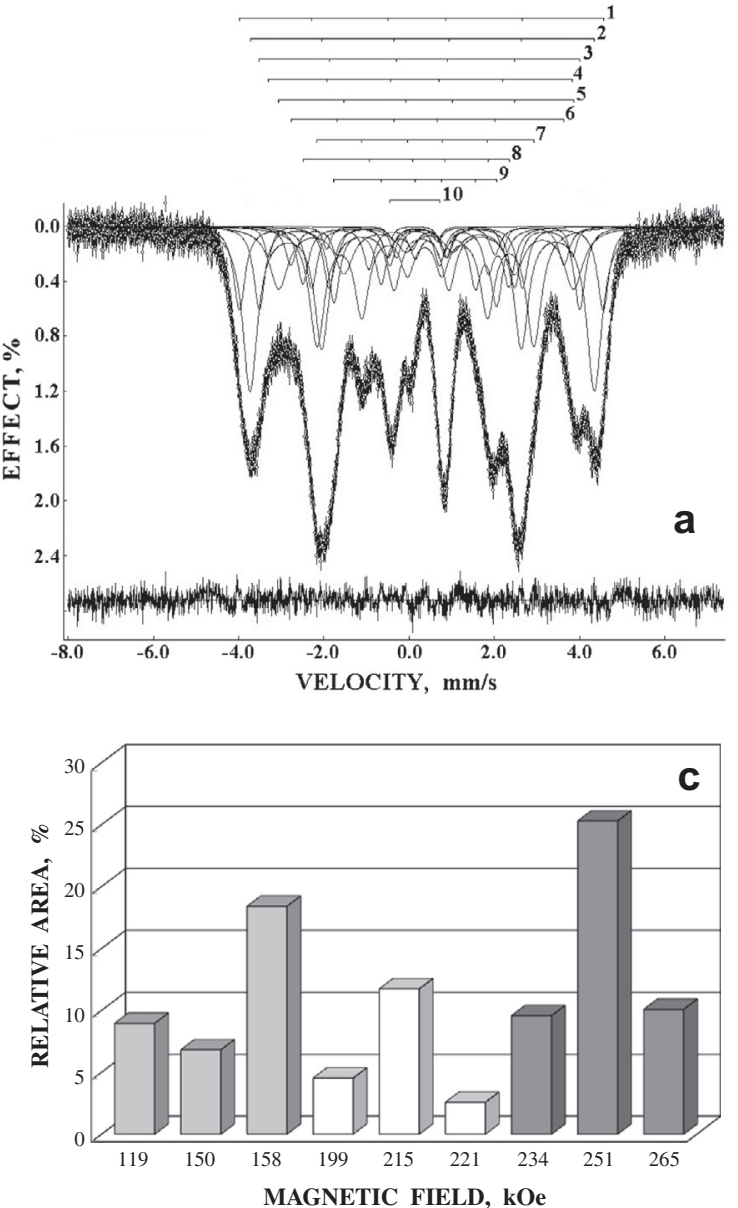
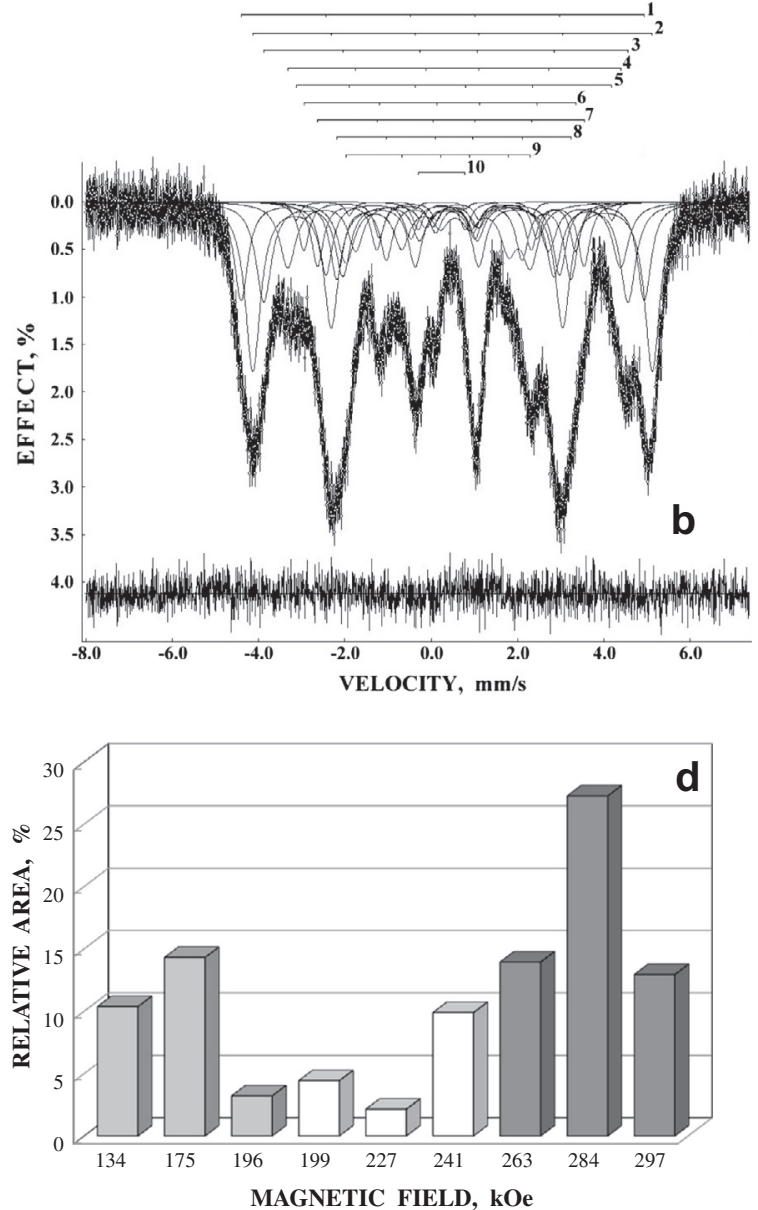

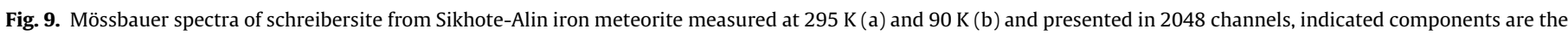

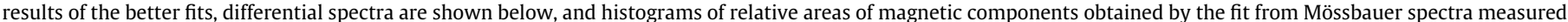
at $295 \mathrm{~K}(\mathrm{c})$ and $90 \mathrm{~K}(\mathrm{~d})$ : $\mathbf{\square}$ - components related to the M1 sites, $\square-$ components related to the M2 sites, - components related to the M3 sites.
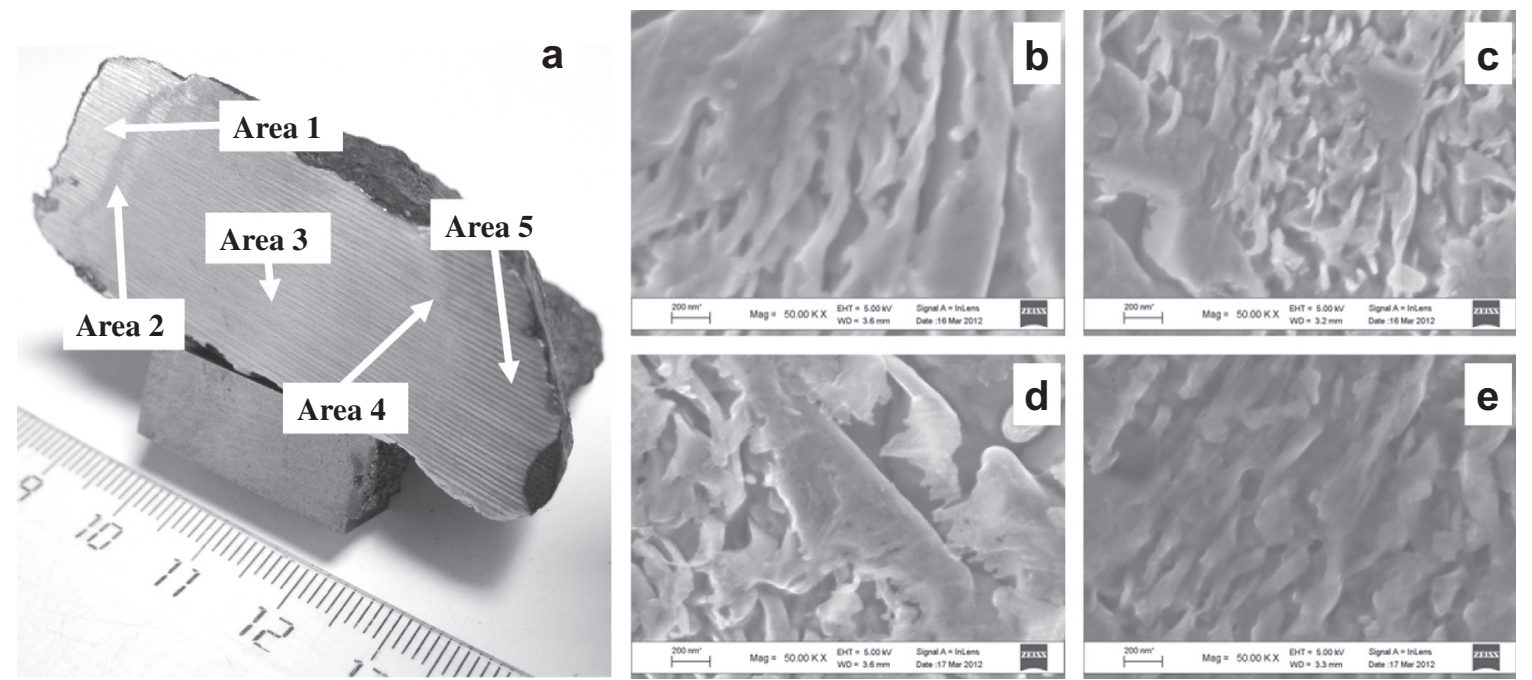

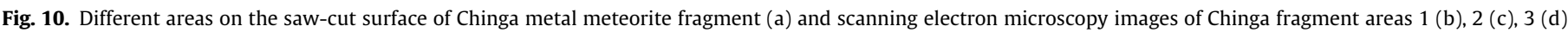
and 5 (e).

nickel phosphide has additional variations in Fe and $\mathrm{Ni}$ occupations of the M2 and M3 sites (M1 site in schreibersite is occupied by Fe atoms only). We evaluated the local microenvironments for each non-equivalent site within the sphere with radius of $3.0 \AA$ (Fig. 8b-d). This result clearly indicates that it takes to take into account the Fe and Ni occupation probabilities for the M2 and M3 

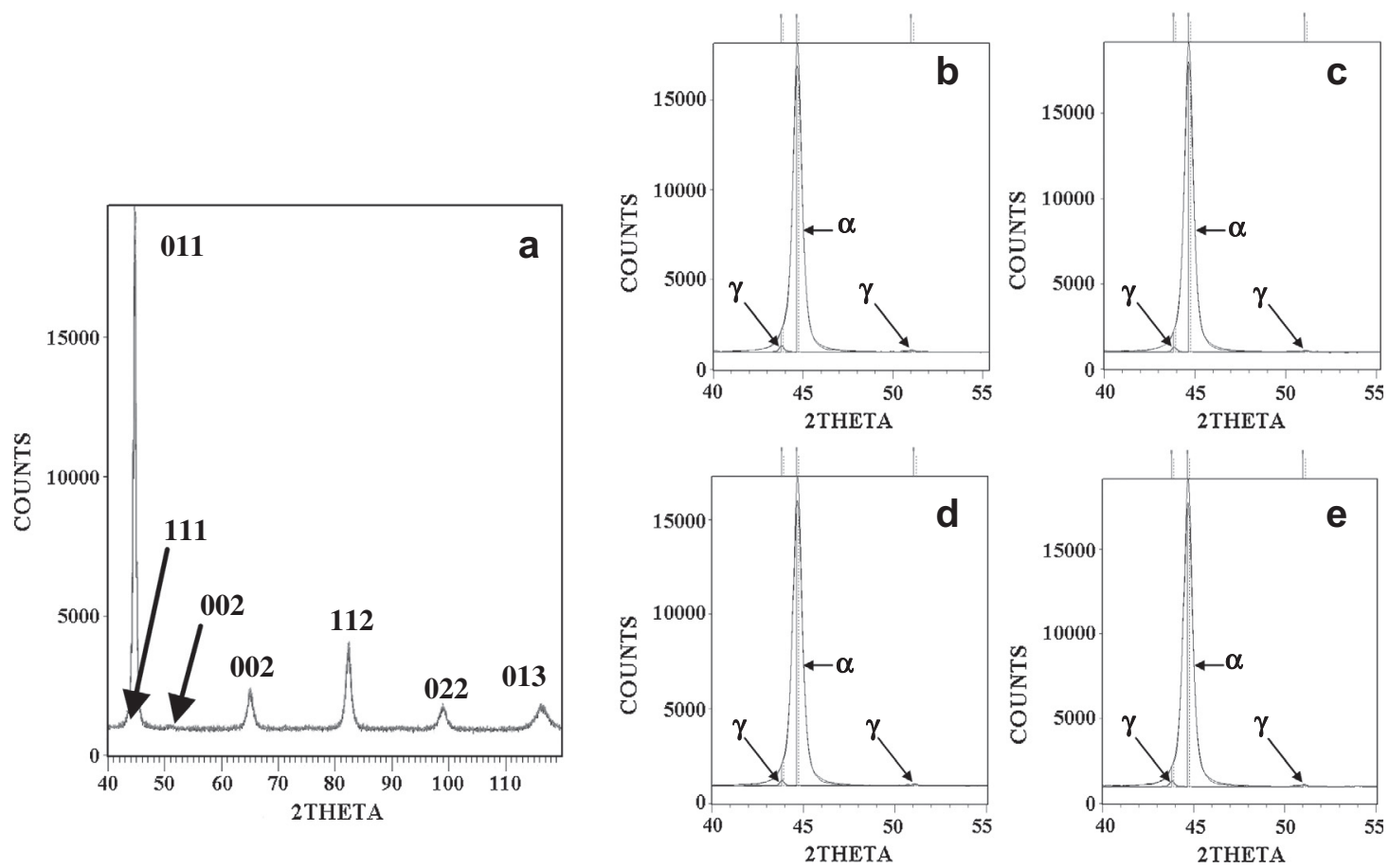

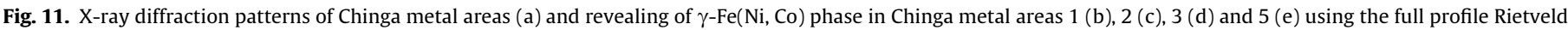
analysis: $\alpha-\alpha-\mathrm{Fe}(\mathrm{Ni}, \mathrm{Co})$ phase, $\gamma-\gamma-\mathrm{Fe}(\mathrm{Ni}, \mathrm{Co})$ phase.

sites in local microenvironment of each site. Therefore, Mössbauer spectra of schreibersite measured at 295 and $90 \mathrm{~K}$ and presented in 2048 channels were evaluated using nine magnetic sextets (Fig. 9a and $b$ ). These fits were better than previous ones made in [19] that can be clearly seen by comparison of differential spectra. To evaluate these results we considered the first approach in which the largest values of $H_{\text {eff }}$ were related to the ${ }^{57} \mathrm{Fe}$ in the M1 sites, the medium values of $H_{\text {eff }}$ were related to the ${ }^{57} \mathrm{Fe}$ in the M2 sites and the lowest values of $H_{\text {eff }}$ were related to the ${ }^{57} \mathrm{Fe}$ in the M3 sites. The histograms of relative areas for magnetic components obtained at 295 and $90 \mathrm{~K}$ are shown in Fig. 9c and d. The total relative areas for each site were: $S_{\mathrm{M} 1}=46 \%, S_{\mathrm{M} 2}=19 \%$ and $S_{\mathrm{M} 3}=35 \%$ at $295 \mathrm{~K}$ and $S_{\mathrm{M} 1}=54 \%, S_{\mathrm{M} 2}=16 \%$ and $S_{\mathrm{M} 3}=28 \%$ at $90 \mathrm{~K}$. The values of both $S_{\mathrm{M} 1}$ and $S_{\mathrm{M} 2}$ obtained at two temperatures were within the error (the $\mathrm{Fe}$ and $\mathrm{Ni}$ occupations cannot vary with temperature while redistribution of magnetic moments may take place). Thus, new results demonstrated the necessity to accounting for either magnetic moment splitting for the ${ }^{57} \mathrm{Fe}$ in the M1, M2 and M3 sites (model [21]) or probabilities of different Fe and Ni occupations of the M2 and M3 sites in the local microenvironments of the M1, $\mathrm{M} 2$ and $\mathrm{M} 3$ sites in the study of schreibersite, $(\mathrm{Fe}, \mathrm{Ni})_{3} \mathrm{P}$, using Mössbauer spectroscopy.

\subsection{Visually different areas on the saw-cut surface of Chinga metal meteorite}

Saw-cut surface of the fragment of Chinga metal meteorite demonstrated several visually different areas which we denoted area 1, area 2 and so on till area 5 (Fig. 10a). The nature of these areas was unknown. We studied these areas except area 4 due to its very thin zone. SEM images of these areas are shown in Fig. 10b-e. These images demonstrated complicated metal phase composition with some morphological differences and variations of dimension of phase regions in different Chinga areas. EDS demonstrated that $\mathrm{Ni}$ concentration was in the range of $\sim 17.5-$ 18.0 at.\% for all areas. XRD patterns of studied metal from various
Chinga areas were the same visually (Fig. 11a). The unit cell parameters were the same within the errors for each area. The tetragonal distortion observed on the basis of the line width was related to the presence of martensite $\alpha_{2}-\mathrm{Fe}(\mathrm{Ni}, \mathrm{Co})$ phase. However, it was possible to reveal small amount of taenite, $\gamma-\mathrm{Fe}(\mathrm{Ni}, \mathrm{Co})$ phase, in addition to the main $\alpha-\mathrm{Fe}(\mathrm{Ni}, \mathrm{Co})$ phase using the full profile Rietveld analysis (Fig. 11b-e). Moreover, the amount of $\gamma-\mathrm{Fe}(\mathrm{Ni}$, Co) phase was different in different areas: $2.6 \%(1), 1.5 \%(2), 1.8 \%$ (3) and 2.3\% (5) (structural refinement was reached with $\chi^{2}$ values in the range of 1.32-1.81 and Bragg factor in the range of 0.61-0.81).

Mössbauer spectra of metal samples from different areas of Chinga meteorite are shown in Fig. 12a-d. These spectra are similar asymmetric six-line patterns resulting from superposition of a large number of magnetic sextets. These spectra were better fitted using the same model of nine magnetic sextets parameters of which appeared to be different for different Chinga areas. It should be noted that differential spectra showed different quality of the fit of the central part of these spectra (between $-1 \mathrm{~mm} / \mathrm{s}$ and $+2 \mathrm{~mm} /$ s). However, additional sextet did not improve the quality of fit. It was interesting to observe differences in the shape of the most negative velocity peak of Mössbauer spectra of various Chinga meteorite areas presented in a scaled-up velocity scale (Fig. 12eh). The main differences can be clearly seen for the first line shape of the spectrum of the sample from area 3. The difference in Mössbauer hyperfine parameters and relative areas for obtained magnetic sextets for studied samples is clearly seen in the histograms in Fig. 13. These results may be related to some variations in metal phase local composition and small variations in $\mathrm{Ni}$ concentration (its redistribution within the total equal concentration). It is possible that this variation in $\mathrm{Ni}$ concentration may be for micron-sized regions of kamacite $\alpha-\mathrm{Fe}(\mathrm{Ni}, \mathrm{Co})$ or martensite $\alpha_{2}-\mathrm{Fe}(\mathrm{Ni}$, Co) phase mainly. The lowest magnetic field components obtained from all spectra (305-309 kOe and 323-326 kOe) may be related to $\gamma-\mathrm{Fe}(\mathrm{Ni}, \mathrm{Co})$ phase regions with different $\mathrm{Ni}$ concentration. Thus, Mössbauer spectra showed some differences in the spectral line shapes and results of the better fit using nine magnetic sextets. 


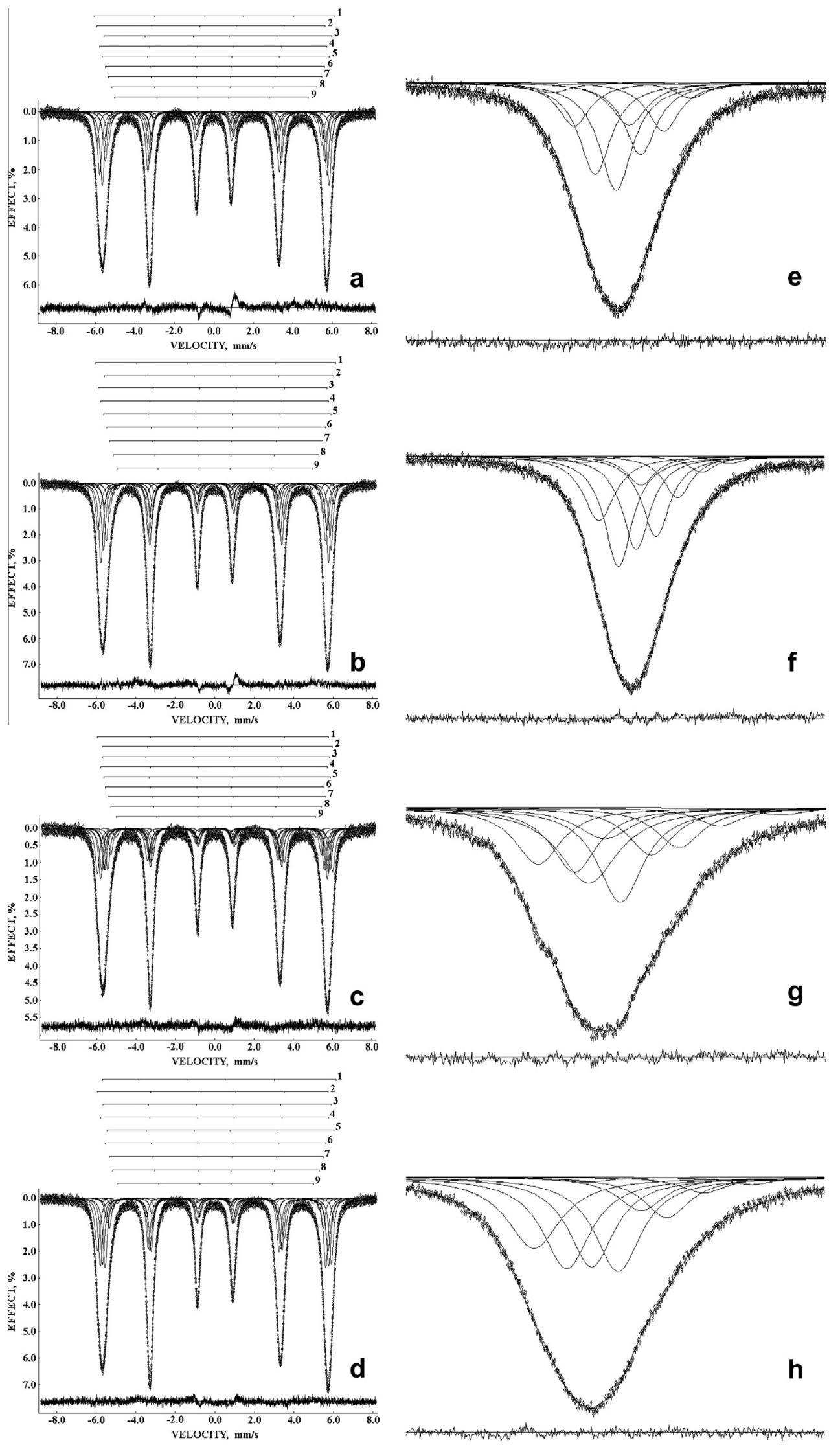

Fig. 12. Mössbauer spectra of Chinga metal samples obtained from the areas 1 (a), 2 (b), 3 (c) and 5 (d) measured at $T=295 \mathrm{~K}$ in 4096 channels and correspondent shape of the most negative velocity peak in the large scale: areas $1(\mathrm{e}), 2(\mathrm{f}), 3(\mathrm{~g})$ and $5(\mathrm{~h})$. Indicated components are the result of the better fit. Differential spectra are shown below. 

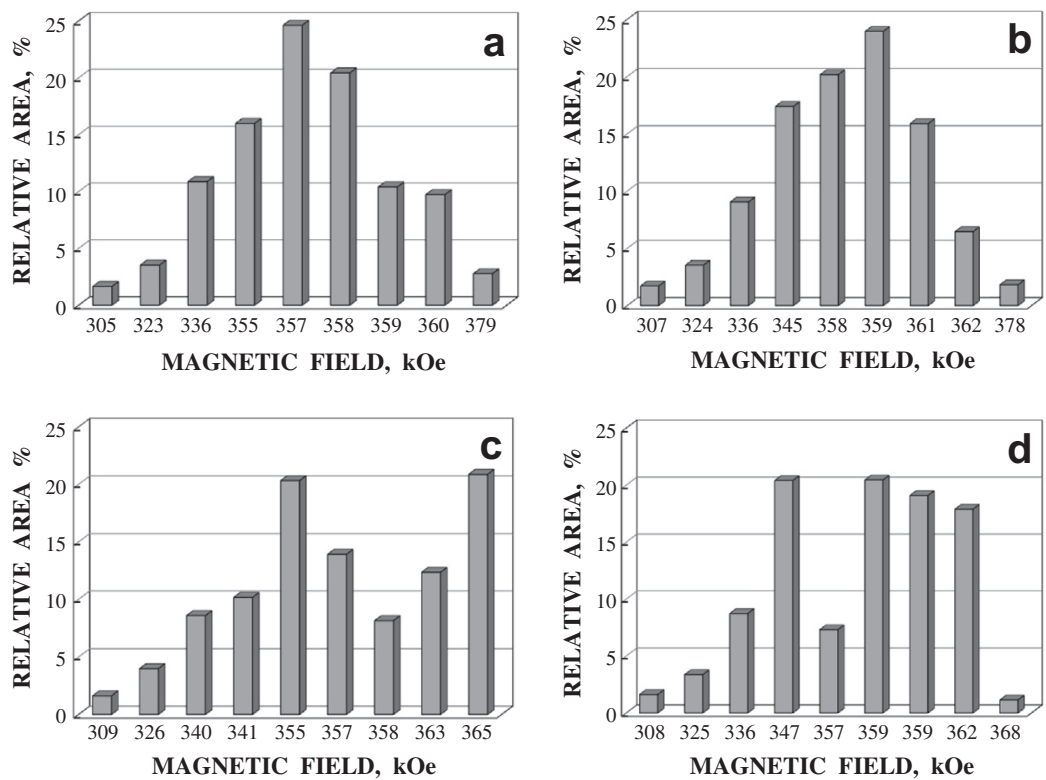

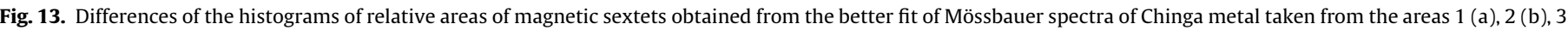
(c) and 5 (d).

Differences in the values of $H_{\text {eff }}$ and $\mathrm{S}$ for spectral components may be related to the differences in the $\mathrm{Fe}-\mathrm{Ni}$ phase composition and local Ni concentration in Chinga metal local microstructures.

\section{Conclusion}

Further application of Mössbauer spectroscopy with a high velocity resolution for study of iron-bearing minerals in meteorites demonstrated again new possibilities in revealing of spectral components which cannot be obtained using the low velocity resolution Mössbauer spectroscopy. In the present study it was possible to observe small variation in hyperfine parameters of the ${ }^{57} \mathrm{Fe}$ in the M1 and M2 sites of olivines in ordinary chondrites and pallasites indicated small structural variations in local environments of these sites in olivines with different origin. The study of schreibersite extracted from Sikhote-Alin iron meteorite, an iron nickel phosphide with three nonequivalent sites M1, M2 and M3, showed that it takes to account for different probabilities of Fe and $\mathrm{Ni}$ occupations of these sites in local microenvironments of each site in addition to ${ }^{57} \mathrm{Fe}$ magnetic moment splitting; however, further investigation is required. Finally, study of metal powders taken from visually different areas on the saw-cut surface of Chinga iron meteorite showed complicated metal structure and differences in Mössbauer parameters which may be related to the variations in metal phase composition and $\mathrm{Ni}$ concentration in micron-sized $\alpha-\mathrm{Fe}(\mathrm{Ni}, \mathrm{Co}), \alpha_{2}-\mathrm{Fe}(\mathrm{Ni}, \mathrm{Co})$ and $\gamma-\mathrm{Fe}(\mathrm{Ni}, \mathrm{Co})$ phases while the nature of these differences is not clear yet. Finally, these studies demonstrated that increase in the spectra measurement time in the case of Mössbauer spectroscopy with a high velocity resolution may be compensated by measurement of Mössbauer spectra with significantly better quality and revealing new information about studying materials.

\section{Acknowledgement}

This work was supported in part by the basic financing from the Ministry of Science and Education of Russian Federation and the
Federal Grant-in-Aid Program "Human Capital for Science and Education in Innovative Russia" (Governmental Contract Nos. 14.740.11.1006 and P1154).

\section{References}

[1] E.L. Sprenkel-Segel, S.S. Hanna, Geochim. Cosmochim. Acta 28 (1964) 1913.

[2] R.B. Scorzelli, Hyperfine Interact. 66 (1991) 249.

[3] M.D. Dyar, D.G. Agresti, M.W. Schaefer, C.A. Grant, E.C. Sklute, Annu. Rev. Earth Planet. Sci. 34 (2006) 83.

[4] M.I. Oshtrakh, V.A. Semionkin, O.B. Milder, E.G. Novikov, J. Radioanal. Nucl. Chem. 281 (2009) 63.

[5] V.A. Semionkin, M.I. Oshtrakh, O.B. Milder, E.G. Novikov, Bull. Rus. Acad. Sci.: Phys. 74 (2010) 416.

[6] M.I. Oshtrakh, V.A. Semionkin, Spectrochim. Acta, Part A: Molec. Biomolec Spectrosc. (2012), http://dx.doi.org/10.1016/j.saa.2012.03.020.

[7] E.V. Zhiganova, V.I. Grokhovsky, M.I. Oshtrakh, Phys. Status Solidi A 204 (2007) 1185.

[8] M.I. Oshtrakh, E.V. Petrova, V.I. Grokhovsky, V.A. Semionkin, Hyperfine Interact. 177 (2007) 65.

[9] M.I. Oshtrakh, V.I. Grokhovsky, K.A. Uymina, V.A. Semionkin, Hyperfine Interact. 177 (2007) 73.

[10] E.V. Petrova, M.I. Oshtrakh, V.I. Grokhovsky, V.A. Semionkin, Hyperfine Interact. 177 (2007) 81

[11] V.I. Grokhovsky, E.V. Zhiganova, M.Yu. Larionov, K.A. Uimina, M.I. Oshtrakh, Phys. Met. Metallogr. 105 (2008) 177.

[12] E.V. Petrova, M.I. Oshtrakh, V.I. Grokhovsky, J. Phys. Chem. Solids 69 (2008) 1790.

[13] M.I. Oshtrakh, E. V Petrova, V.I. Grokhovsky, V.A. Semionkin, Meteorit. Planet. Sci. 43 (2008) 941

[14] M.I. Oshtrakh, M.Yu. Larionov, V.I. Grokhovsky, V.A. Semionkin, Hyperfine Interact. 186 (2008) 53.

[15] M.I. Oshtrakh, E.V. Petrova, V.I. Grokhovsky, V.A. Semionkin, Hyperfine Interact. $186(2008) 61$.

[16] V.I. Grokhovsky, M.I. Oshtrakh, E.V. Petrova, M.Yu. Larionov, K.A. Uymina, V.A. Semionkin, Eur. J. Mineral. 21 (2009) 51.

[17] D.G. Patrusheva, M.I. Oshtrakh, E.V. Petrova, V.I. Grokhovsky, V.A. Semionkin, Hyperfine Interact. 197 (2010) 295.

[18] M.I. Oshtrakh, M.Yu. Larionov, V.I. Grokhovsky, V.A. Semionkin, J. Alloys Compos. 509 (2011) 1781.

[19] M.I. Oshtrakh, M.Yu. Larionov, V.I. Grokhovsky, V.A. Semionkin, J. Mol. Struct 993 (2011) 38.

[20] M.I. Oshtrakh, M. Yu. Larionov, V.I. Grokhovsky, V.A. Semionkin, Mater. Chem Phys. 130 (2011) 373.

[21] E.J. Lisher, C. Wilkinson, T. Ericsson, L. Haggstrom, L. Lundgren, R. Wappling, J Phys. C: Solid State Phys. 7 (1974) 1344. 